\title{
Synthesis and electrochemical properties of nanostructured nickel-cobalt oxides as supercapacitor electrodes in aqueous media
}

\begin{abstract}
Co-precipitation method was adopted in the preparation of nickel-cobalt oxides for potential application in supercapacitors. The formation of spinel nickel-cobalt oxide, NiCo2O4 started below $400{ }^{\circ} \mathrm{C}$ as confirmed by $\mathrm{X}$-ray diffraction analysis. Pure phase nickel cobaltite with cation ratio of $1: 2(\mathrm{Ni}: \mathrm{Co})$ was obtained at calcination temperature of $400{ }^{\circ} \mathrm{C}$. The spinel phase decomposed gradually until $700{ }^{\circ} \mathrm{C}$. The calcination time for the formation of $\mathrm{NiCo} 2 \mathrm{O} 4$ was found to be between 2 to $4 \mathrm{~h}$. The particle size of the prepared sample studied by transmission electron microscopy showed a value of $9.47 \mathrm{~nm}$. The electrochemical properties of the metal oxide were measured in various acidic, neutral and alkaline electrolyte systems (1.0 M HCl, $1.0 \mathrm{M} \mathrm{KCl}$ and $1.0 \mathrm{M} \mathrm{KOH})$ by employment of cyclic voltammetry, galvanostatic charge-discharge test and electrochemical impedance spectroscopy. Ideal capacitor behaviour with the largest operating voltage of $1.0 \mathrm{~V}$ and good electrochemical stability were observed in $\mathrm{NiCo} 2 \mathrm{O} 4$ using neutral $\mathrm{KCl}$ aqueous electrolyte. Meanwhile, the prepared sample displayed the highest surface redox activity in $1.0 \mathrm{M} \mathrm{KOH}$ alkaline electrolyte but showed the lowest electrochemical performance in acidic electrolyte. At the current density of $0.5 \mathrm{Ag}-1,1.0 \mathrm{M} \mathrm{HCl}, 1.0 \mathrm{M} \mathrm{KCl}$ and $1.0 \mathrm{M} \mathrm{KOH}$ gave specific capacitance values of $3.8,41.9$ and $249.8 \mathrm{~F} \mathrm{~g}-1$ respectively.
\end{abstract}

Keyword: Electrochemical impedance spectroscopy; Electrochemical reactions; Nanostructured materials; Precipitation; Transmission electron microscopy; X-ray diffraction 